\section{Lactic Acid Formation and Carbon Dioxide Fixation}

Is an investigation, first into the composition of the internal atmosphere of successively lower regions of the plant body of Equisetum limosum, and secondly into the respiratory metabolism of the perennating rhizomes of this plant, a very interesting relationship between lactic acid formation and carbon dioxide fixation has emerged.

The plants studied grew in standing water, $1-1.5 \mathrm{~m}$. deep with their perennating rhizomes extending in the bottom mud to a depth of up to $20 \mathrm{~cm}$. This constituted a very markedly anaerobic environment. The internal atmosphere of the rhizome was rich in carbon dioxide and low in oxygen, the carbon dioxide concentration ranging between 5 and 8 par cent and the oxygen concentration between 2 and 8 per cent.

The rate of respiration of internodes of rhizome tissue was studied over a three-day period in various concentrations of carbon dioxide with an oxygen tension generally fixed at 5 per cent. Respiration was also studied in air and nitrogen. After the threeday period of respiration, the organic acids, $\alpha$-keto acids and alcohol-soluble sugars were extracted from the tissue, separated chromatographically and estimated.

In Table 1 the amounts of lactic acid present in tissue allowed to respire in the dark at $25^{\circ} \mathrm{C}$. under various gaseous conditions are given, together with the respiratory quotients obtained over the three-day respiratory period. It will be seen that a trace of lactic acid was present after respiration in a mixture of 2.5 per cent carbon dioxide and 5 per cent oxygen. No lactic acid was found in material allowed to respire in gas mixtures containing 3-12 per cent carbon dioxide with 5 per cent oxygen, nor in a mixture of 20 per cent oxygen and 3 per cent carbon dioxide.

The presence of a lactic dehydrogenase was demonstrated in a particulate suspension prepared according to the method of Davis ${ }^{1}$.

The low respiratory quotients given by tissues in the presence of carbon dioxide suggested that carbon dioxide fixation may well have been occurring. This was investigated by making an autoradiograph of a chromatogram of the organic acids extracted from tissue that htd been allowed to respire for $12 \mathrm{hr}$. in a mixture of 5 per cent oxygon and 7 per cent carbon dioxide containing a very small fraction carbon-14 labelled carbon dioxide. The autoradiograph gave a clear indication of carbon dioxide fixation, as there was labelling in malic, citric and succinic acids and in two unknown acids, one of which was tentatively identified as $\beta$-hydroxy butyric acid.

Thus the presence of lactic acid has been demonstrated only in tissues where it seemed unlikely that carbon dioxide fixation had occurred.

Table 1. Respratory QUOTIENTS aND LaCTio ACID Content

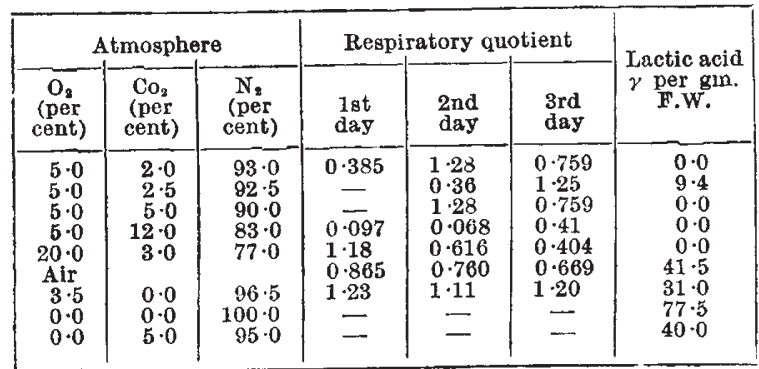

Carbon dioxide fixation, whether by the malic enzyme as demonstrated by Conn et al. ${ }^{2}$ or by a modified Wood-Werkman reaction described by Wood $^{3}$ and Utter ${ }^{4}$ depends upon the $\beta$-carboxylation of pyruvic acid. It may well be, therefore, that where carbon dioxide fixation occurs there is a competition for pyruvic acid, by the processes of lactic acid formation and carbon dioxide fixation. There is, however, a second possibility, for Ochoa et al. ${ }^{5}$ have demonstrated a coupled process of lactic acid oxidation and carbon dioxide fixation in pigeon-liver extracts.

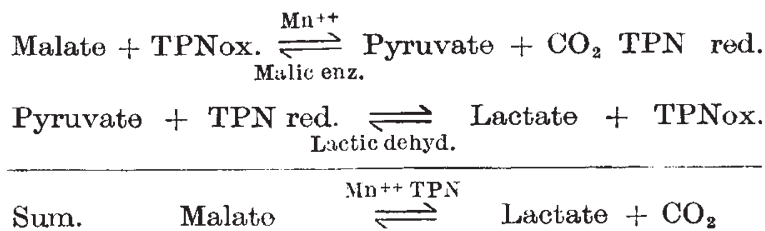

Korkes et al. ${ }^{6}$ have demonstrated an essentially similar DPN specific malic enzyme/lactic dehydrogenase system in Lactobacillus arabinosus.

In general ecology of such a plant as Equisetum, it would plainly be of value if it possessed a mechanism whereby the two processes of lactic acid formation and carbon dioxide fixation competed for pyruvic acid. It would be equally important if there existed a TPN- or DPN-linked dismutation between malic acid and pyruvic acid through the combined action of the malic enzyme and the lactic dehydrogenase system. The fixation of respiratory carbon dioxide conserves the carbon of the rhizome, maintaining the levels of the organic acids, and if, as suggested, the process is linked to lactic acid oxidation, it would prevent the build-up of that fermentation product.

This work, which was carried out in the Department of Botany, University of Liverpool, under the supervision of Mr. D. A. Coult, will be reported in full elsewhere. It is a pleasure to acknowledge my indebtedness to Mr. D. A. Coult and Prof. N. A. Burges for their interest in this work and to Dr. W. O. James of the Department of Botany, University of Oxford, for his interest and kindness in giving me the facilities of his laboratory in which to learn the necessary chromatographic techniques. I am grateful to the Department of Scientific and Industrial Research for financial assistance.

Radiobiological Research Unit,

D. A. Barber

Atomic Energy Research Establishment, Harwell.

1 Davis. D. D., J. Exp, Bot., 4, 173 (1953).

${ }^{2}$ Conn, E., Vennesland, B., and Kraemer, L. M., Arch. Biochem., 27, 179 (1949)

s Wood, H. G., Soc. Exp. Biol. Symposium, 5, 9 (1951).

4 Utter, M. F., J. Biol. Chem., 188, 847 (1951).

s Ochoa, S. Mehler, A. H., and Kornberg, A., J. Biol. Chem., 174, 979 (1948).

- Korkes, S., del Compillo, A., and Ochoa, S., J. Biol. Chem., 187, 891 (1950).

\section{Narcotic Activity of Optical Enantiomorphs of Methylpentynol}

THE opticel resolution of $d l$-3-methylpent-1-yn-3-ol was achieved for the first time by one of us ${ }^{1}$ some two years ago, and it seemed of interest to determine whether the narcotic activity of the optical antipodes differed, in spite of the contrary finding in the 